\title{
New data on Paenelimnoecus from the middle Miocene of Spain support the shrew subfamily Allosoricinae
}

Lars W. van den Hoek Ostende, Marc Furió, and Israel García-Paredes

Acta Palaeontologica Polonica 54 (1), 2009: 159-164 doi:http://dx.doi.org/10.4202/app.2009.0117

Limnoecus truyolsi was long considered an enigmatic shrew. Additional material from the Calatayud-Montalbán Basin

(Spain) shows it to be referable to the genus Paenelimnoecus. The species represents an intermediate form between $P$. micromorphus and $P$. crouzeli. This lineage confirms the separate development of the "soricine" p4, and thus supports the Allosoricinae as a separate subfamily.

Lars W. van den Hoek Ostende [Hoek@Naturalis.nl], Nationaal Natuurhistorisch Museum, Naturalis, Postbus 9517, NL-2300 RA Leiden, The Netherlands;Marc Furió [marc.furio@icp.cat], Institut Català de Paleontologia, Universitat Autònoma de Barcelona, Mòdul ICP (Espina B3 bis parell) E-08193 Cerdanyola del Vallès, Barcelona, Spain.;Israel García-Paredes [Paredes@ Naturalis.nl], Nationaal Natuurhistorisch Museum, Naturalis, Postbus 9517, NL-2300 RA Leiden, The Netherlands.

This is an open-access article distributed under the terms of the Creative Commons Attribution License (for details please see creativecommons.org), which permits unrestricted use, distribution, and reproduction in any medium, provided the original author and source are credited. 